\title{
Impact of the Covid-19 pandemic on the requirements for accounting and analytical support of business
}

\author{
Roman Chugumbaev ${ }^{1, *}$, and Nina Chugumbaeva ${ }^{2}$ \\ ${ }^{1}$ Moscow state University of Humanities and Economics, Losinoostrovskaya Str., 49, 107150 \\ Moscow, Russia \\ ${ }^{2}$ MIREA - Russian technological University, Vernadsky Avenue, 78, 119454 Moscow, Russia
}

\begin{abstract}
This article proposes to get acquainted with a study that, as a first approximation, assesses the impact of the Covid-19 pandemic on a shift in emphasis in accounting and analytical work. Economic actors once again found themselves in the conditions of a "new normalcy", now it is a global coronavirus crisis. Now society and business are faced with new risks, threats, disasters, opportunities, unforeseen consequences of the COVID-19 pandemic. Of course, the management of the companies is expected to provide the creative solutions, an economically sound strategy or a policy of working in a new environment. The new complex context of decision-making caused by the pandemic needs to keep information and analytical support up to date. Therefore, this article proposes to pay attention to some aspects of information and analytical work that are of particular importance during the period of the impact of the pandemic and its consequences. The list of such aspects includes the mechanisms for ensuring business transparency, the application of stakeholder theory and change management theory, the organization of a systematic business analysis, the concept of social responsibility and ESG criteria. This approach will make it possible to "reveal" the problems caused by the pandemic and its consequences, find the best solutions therefor, implement them correctly and update the business development strategy. The research results based on the analysis of current business needs will help build an adequate system of accounting and analytical support.
\end{abstract}

\section{Introduction}

The impact of the pandemic on the costs of human capital, on which economic success largely depends [9], is catastrophic. At the end of March 2020, the State Duma of the Russian Federation adopted a package of laws to combat the consequences of the coronavirus. This time was the beginning of another "new reality" for Russian society and business, when a significant reassessment of priorities and values took place. For now, the COVID-19 pandemic is not receding, raising the level of uncertainty about the economic

* Corresponding author: romanry@ya.ru 
impact of the crisis. COVID-19 continues to spread across the world, with countries facing a general economic downturn, rising unemployment rates and declining business confidence. Since these difficult conditions of functioning can persist for a long period and have a long-term negative impact on the economy of organizations, a high-quality system of information and analytical support is needed, which allows to initiate changes in a timely manner and make an economically sound choice of decisions. The success of overcoming the economic crisis caused by the consequences of a protracted pandemic depends thereon.

Given the above, the purpose of the study is to analyze the impact of the COVID-19 pandemic on the needs of information and analytical support of business, namely, its content, priority principles and approaches.

\section{Methods}

This study offers an initial scientific look at the information and analytical needs of the company managers in a new complex context full of uncertainty and risks. Based on rather limited and recent studies published in the works of domestic and foreign authors and presented at scientific conferences in 2020, as well as on the expert opinion of the specialists who are faced with the problems of making managerial decisions in a pandemic, the most obvious features of the functioning of a business in a new context have been revealed. This study does not claim to provide a sufficiently complete coverage of all issues of accounting and information support. Rather, it is one of the initiatives, which will be followed by further research, both theoretical and empirical, in the field of accounting, analysis and audit of the activities of economic entities in the new conditions.

Currently, high uncertainty affects the need for high-quality information and analytical support for company management. Within the framework of this study, it is proposed to focus attention on some elements of information and analytical work, which, in our opinion, are of particular value for management during a pandemic and the subsequent period of combating its consequences. The list of these elements included as follows:

- application of the mechanisms for the transparent functioning of business;

- analysis and monitoring of the stakeholders' requirements;

- information and analytical support for change management;

- systematic business analysis;

- focus on social responsibility and ESG criteria.

\section{Mechanisms for transparent business functioning}

The transparent functioning of economic agents [8] in a pandemic is more important than ever as it provides a link with the key business stakeholders. Trust between participants in economic processes is declining under the new conditions. The acute phase of the pandemic in Russia has shown that business and the state in such times need a significant "rapprochement" in order to unite the efforts to ensure the socio-economic sustainability. Mutual transparency is a prerequisite for such convergence. Equally important is the transparency of business intentions and the financial condition of economic entities in relations with banks, which are also committed to a more cautious policy and are more attentive to the borrowers. In a period of high uncertainty and turbulence in the business environment, all the participants in social and economic processes need the reliable, understandable and timely information.

The transparent operation of the company during such a period significantly reduces the likelihood that supervisory authorities, representatives of state authorities, without notification, initiate unscheduled control and audit activities. During a pandemic, such 
measures are taken much more often than usual, which, of course, can be burdensome for organizations, when many other complex problems that require high attention already arise. Transparency also reduces or even completely eliminates actions that are aimed at abuse and gaining vested interests due to the chaos and uncertainty caused by pandemic consequences and panic in a society. Transparency ensures the authenticity of information about an organization, and during a pandemic, there is a high proportion of fake information in the media space [7]. The openness and transparency of the organization's functioning reduce the consequences of an "information attack" on the part of competitors and other actors in the dissemination of negative information about the company. A more accelerated transition to remote management, remote work during and after a pandemic also requires ensuring the transparency of online business processes. Such internal transparency becomes a prerequisite for the coordinated and efficient functioning of the business. To ensure business transparency on a systematic basis, work should be organized in several directions, in which there is a significant amount of application of analytical procedures [1].

All this indicates a rather high need for the formation and development of systematic processes in economic entities aimed at the formation of transparent information, incl. reporting. It is necessary to provide analytical processing of disclosed information so that key stakeholders receive conveniently organized and understandable information in which you can quickly and easily highlight the relevant part for making decisions in such a difficult period.

\section{Consideration of stakeholders' requirements}

During a pandemic, "harsh" decisions by the stakeholders do not always take into account the interests of the business, and sometimes create problems that also require a prompt response. At the same time, it is necessary to be able to monitor both internal and external elements of the business environment online using modern information and communication tools.

Thus, some studies confirm that the pandemic has led to a change in consumer behavior [3], which has intensified the search for a differentiated offer, aiming for a greater variety of the products. The very nature of the organization of interaction with customers has changed. Consideration should be given to the changing needs of the customers during the periods of special treatment and restrictions. During the period of the pandemic, the company must not miss the opportunity to reach a new level of trusting relationships with the personnel, the requirements of which are contradictory due to the general uncertainty of the present and the future. Suppliers and contractors in the new environment can, like everyone else, change requirements, priorities, etc., and therefore, you should very carefully monitor the supply chain and be in contact with them.

During a pandemic, various company transformations are required, focused on highly responsible functioning, taking into account the requirements of all key stakeholders. At the same time, the aforementioned requirements for business transparency are also due to the expansion of the circle of stakeholders, who are increasingly actively involved in the management decision-making processes. Since the functioning of a modern company is focused on meeting the requirements of a wide range of stakeholders, it is very important to provide them with information that allows them to give an adequate assessment of alternative solutions. Therefore, one should carefully consider the composition of key stakeholders, and ensure that their requirements are systematically monitored [2]. Consistency is necessary due to the fact that the requirements of stakeholders are subject to change, as well as the influence of external conditions. The consequences of restrictive measures from a pandemic significantly change the context of the operation and 
development of a business and require timely consideration of changes in the requirements of stakeholders.

\section{Managing changes during COVID-19}

During a pandemic, we all are faced with challenges, changing the way we do business. In the context of such a massive transition to remote forms of interaction, the transfer to the Internet of some business processes, restrictions on the part of government bodies, many problems and obstacles are obvious in all areas of business functioning: financial, investment and operational ones. But along with the negative aspects that lie on the surface, it is important to see new opportunities, the advantages of the resources available to economic agents. All organizations, including business entities, are trying to initiate and implement changes of varying complexity in order to find a way out of the problems of the negative impact of the pandemic. As you know, it is customary to distinguish transactional organizational changes from transformational ones. At the same time, most of the changes in a pandemic are transformational in nature. If transactional changes focus on individual organizational problems, then transformational ones are more systemic and cover the company as a whole. The need to implement the significant transformational decisions predetermines the need for accountants and analysts to know the provisions of the theory of change management. In a pandemic environment, transformational changes should be based on an analytically grounded and responsible strategy that takes into account the most relevant trends in the organization's functioning environment. To build and implement a strategy that can effectively manage the innovative changes of an enterprise in conditions of overcoming the impact and the consequences of a pandemic, it is necessary to solve the problems of the quality of analytical support:

1. At the stage of initiating changes, the company's management must see the prerequisites for certain directions of organizational changes and take the initiative in a timely manner. It is important for economic agents to recognize the incoming signals for the implementation of changes, to understand their role at this stage of business development and its functioning environment. During a pandemic, there are many different quite clear signals for change. New conditions and restrictions pose challenges for economic entities to master new methods of work, remote methods of personnel control, interaction with partners, methods of delivering goods to customers, etc. Many spheres of entrepreneurial activity have to completely change the business model of their functioning, as well as other strategic elements of the business. The management system of Russian enterprises should be provided with information and analytical tools aimed at identifying the prerequisites for changes in the current regime;

2. At the stage of planning changes, the company's management is faced with the problems of criteria-based assessment of the necessary changes, as well as with the problem of justifying the selection of decisions during the design of changes. Most of the changes during a pandemic are aimed at business survival, which implies a particular importance of sustainability indicators in various aspects, incl. financial and operational ones. We are witnessing when companies, based on taking into account the new operating context, choose to implement the initiatives related to a temporary change in their business focus and produce, on a temporary basis, those products and services that are not inherent in their area of competence. So some companies have decided to produce personal protective equipment, masks, hand sanitizers, etc.;

3. At the stage of implementing the changes, problems arise of how to assess the effectiveness and efficiency of implementation, when a decision should be made on the necessary adjustments; 
4. At the stage of assessing the results of the implementation of an innovative solution, it is necessary to assess whether the goals of changes have been achieved and what solutions should be implemented in order to continue the improvement strategy.

\section{Business analysis on a systematic basis}

A significant transformation of the conditions for the functioning of a business requires the development at the enterprise of a mechanism for initiating and implementing changes, which is possible if the enterprise carries out a systematic business analysis [6]. Business analysis is a new direction of analytical science and a new type of professional activity, a key element of which is monitoring and analysis of the level of necessary and actual fulfillment of the requirements of stakeholders, as well as the possibilities of increasing it through innovative solutions. It appeared as a natural stage in the development of domestic complex economic analysis for the conditions of a turbulent socio-economic environment, characteristic of a modern market economy. The sustainability of a company during a pandemic depends on the number of its key stakeholders, whose requirements become the basis for making decisions on changes in the company. An in-depth study of stakeholder requirements is a strategic objective and is closely related to the categories of strategic management. Business analysis allows you to stay focused in favor of speculative decisions with short-term benefits during a pandemic. On the contrary, by studying the strategic preferences and vision, it identifies the requirements of key stakeholders as the main guideline for implementing changes that would allow to acquire long-term benefits, to recognize the true values for key stakeholders. By monitoring and in-depth analysis of stakeholders' requirements, business needs and identifying business problems, strategic guidelines and vision of the company contribute to its real development in difficult times, and not succumb to chaos and make "short-sighted" decisions.

\section{Social responsibility concept and ESG criteria}

Several decades ago, when the crisis hit, not only medium-sized, but also large companies and corporations could afford to stop activity and even take a "step back" in areas of activity reflecting the social responsibility. However, now that the role of business in society has evolved significantly, companies must take care of preserving social and environmental capital. During a pandemic, the attention of the public and government regulators to business decisions emphasizes the special role of the concept of social responsibility of business [5] and control of ESG criteria (Environmental, Social, Governance,), especially highlighting the S-factors [4]. During a pandemic, organizations can take advantage of opportunities to be socially responsible and "closer" to society. The conditions in which economic agents find themselves become a test of their real commitment to the principles of sustainability and social responsibility. The attitude of the management to the safety of personnel in the workplaces of their own personnel, the transition to remote work, the provision of PPE and more can reflect a lot about the real concern of the company towards the employees. During a pandemic, many large Russian companies initiate various measures aimed at overcoming the consequences of the pandemic. Some companies carry out the initiatives aimed at supporting healthcare institutions, modernizing intensive care units, purchasing additional equipment and consumables, and personal protective equipment for these institutions. Dignified responsible attention and care of the company in relation to personnel, consumers, suppliers, society and all key stakeholders can remain in the memory of society for a long time and become a reliable social capital that ensures long-term business sustainability. It is 
clear that the pandemic, in addition to ample opportunities to prove its commitment to responsible, ethical and transparent operation, also poses the threats to business survival. These problems often reach the point where companies are forced to focus on their core operations rather than investing in corporate social responsibility projects. In this regard, there are the prerequisites for an even greater shadowing of the activities of some companies, as well as the use of panic in a society and an increased degree of uncertainty, turbulence of the economic context in speculation and other abuses for the sake of shortterm success. These circumstances cannot be ignored by the company's accounting specialists.

\section{Conclusion}

Thus, in this study, some aspects of accounting work have been noted, which have acquired new relevance for company management in a pandemic. However, there is no doubt that the current experience and the subsequent consolidation of business cases will allow further research on this issue. Concluding this article, we ask the academic community to take part in a thorough study of the problems of information and analytical support of the business. In our opinion, the problem of developing mechanisms for ensuring business transparency during a pandemic remains difficult. In applying the stakeholder approach, the problem of standardizing measurements of various stakeholder requirements has not been solved, the solution of which will open up broad opportunities for comparative analysis of innovations. In addition, it is difficult to determine the real, not exaggerated, stakeholder requirements. For the proper dissemination and application of the principles of sustainable development and social responsibility in Russian enterprises, research is needed to address the role of institutional elements of the functioning environment, such as analytical and rating the agencies, and business associations.

\section{References}

1. E. Alloa, Transparency, Society and Subjectivity. - Palgrave Macmillan, Cham, 21 (2018)

2. R. E. Freeman, Strategic Management: A Stakeholder Approach, 292 (1984)

3. J. Kim, Australasian Marketing Journal (AMJ), 28(3), 108 (2020)

4. E. Ortas, I. Álvarez, A. Garayar, Sustainability, 7(2), 1932 (2015)

5. J. M. Palma-Ruiz, J. Castillo-Apraiz, R. Gómez Martínez, International Journal of Financial Studies, 8(3), 41 (2020)

6. V.I. Barilenko, M.V. Melnik, R.P. Bulyga, E.B. Gerasimova, O.V. Efimova, V.P. Nevezhin, V.V. Berdnikov, Fundamentals of business analysis , 270 (2018)

7. O.S. Deineka, L.N. Dukhanina, A.A. Maksimenko, European Scientific Conference, 326 (2020)

8. O.V. Rozhnova, In the collection: IFRS in Russia as a new intellectual environment, The view of the professional community, 58 (2018)

9. P.D. Shishmanova, Russian technological journal, 8(4), 141 (2020) 